\title{
Influence of Planning in Oral Teaching Methods
}

\author{
Elena Vladimirovna Litvinenko ${ }^{1}$, Liliia Saimovna Sirazova ${ }^{1} \&$ Jamil Eftim Toptsi $^{2}$ \\ ${ }^{1}$ Kazan Federal University, Russia \\ ${ }^{2}$ Eötvös Loránd University, Hungary \\ Correspondence: Elena Vladimirovna Litvinenko, Kazan Federal University, Russia. E-mail: lena2703@inbox.ru
}

Received: July 17, 2019

doi:10.5430/ijhe.v8n7p56
Accepted: October 12, $2019 \quad$ Online Published: October 28, 2019

URL: https://doi.org/10.5430/ijhe.v8n7p56

\begin{abstract}
The mixed methods study presented in this paper investigates the influence of planning in oral teaching methods.. This research article presented examines the impact of planned and unplanned conditions on three different variables in the context of oral teaching methods: fluency, vocabulary complexity, and accuracy. As a research tool two narrative tasks were used which required the participant construct linguistic forms based on visual information, requiring the use of the participant's imagination. With the help of qualitative content analysis, the most common 'pattern-finding' moves were described from the collected data in detail. In order to compare data from unplanned and planned conditions, three analyses were conducted with the help of three software tools: D-tool, P-lex, and Coh-Metrix. The results showed that pre-task planning time had a positive effect on lexical sophistication and accuracy. However, fluency under unplanned conditions was greater than under planned conditions, suggesting that the planning process does not produce a strong impact on fluency. According to most of the participants, they paid close attention to the logical order of the pictures, organization of ideas, and the coherence of their utterance while using their individual planning time.
\end{abstract}

Keywords: oral performance, narrative task, vocabulary complexity, accuracy, fluency

\section{Introduction}

In recent years, the interest in conducting research on task-based language learning and teaching has increased. Birch (2005), Ellis (2003), Foster, Tonkyn and Wigglesworth (2000) are just some part of a considerable list of scholars who have made contributions to this research area. One of the main aims of the teacher of a foreign language is to use a wide range of tasks in the teaching process in order to form students' foreign language communication competence and to make training more effective. However, this raises the question of which characteristics of a 'task' make it an important element for conducting a research. A definition of task can shed some light on this issue. According to Long (2014), a task is something that needs to be planned or designed by taking the needs of the students into consideration. Based on this definition, it can be perceived that people who are learning a new language need to solve tasks, which can provide a rich source of information that can allow researchers to measure three linguistic aspects such as fluency, accuracy, and complexity, among others. Influenced by the research development on task-performance, the aim of this research is to investigate the impact of planned and unplanned conditions on different variables of fluency, vocabulary complexity, and accuracy to complete the tasks successfully in the context of oral teaching methods. The following questions reflect the aims of this research:

1) What is the role of planning on different variables of fluency, vocabulary complexity, and accuracy in oral teaching methods?

2) What do students focus on during individual planning time?

\section{Methods}

Instruments

Two narrative tasks were used to gather data for the study. A set of six pictures were given to a group of two individuals, who had to construct a story from a set of six pictures that were not obviously connected and relay the ideas to each other. These tasks included turning novel visual information into linguistic forms and required some degree of imagination, and demanded cognitive effort and concentration of attention. For data collection, unobtrusive voice recorders were used with external microphones in order to record the students' answers. 


\section{Participants}

The current study involved 8 MA students of English Studies from Eötvös Loránd University. They came from a wide variety of L1 backgrounds and were all between 20-30 years old, and all but two were female. All participants in the study possessed an advanced level of English.

Procedure

The first phase of experiment required students to complete the task with only a brief introduction to ensure that they understood what was required of them. In the second phase of experiment, students were given the same brief introduction, followed by 3 minutes of individual planning time to consider vocabulary complexity, content, and the organization of the story. After completing the tasks, students were distributed sheets of paper in order to answer the following question: "What do you focus on during individual planning time?" In this way, it was possible to investigate what students focused on while preparing for their tasks.

Analysis

After the recording process, all data were transcribed and closely analyzed and reread many times, with different focuses in mind. The performance of students on the narrative task under planned and unplanned conditions was compared. Data was described and coded for the following variables:

\section{Fluency}

Speech rate: the total number of syllables produced by the participant divided by the total amount of time, including pause time, required to produce the text.

Vocabulary complexity: the number of clauses, vocabulary diversity, density, and sophistication of lexical performance.

\section{Accuracy}

Ratio of error free clauses: the number of grammatically correct clauses divided by the total number of clauses.

Given the focus of the study on unplanned and planned conditions, three analyses were carried out using the electronic tools D-tool and P-lex (measuring vocabulary diversity), and Coh-Metrix (measuring speech rate). For accuracy, the ratio of the number of grammatically correct clauses and the total numbers of clauses was calculated to obtain the ratio of error free clauses. The purpose was to generate three measures of oral performance: fluency, vocabulary complexity, and accuracy for each task and to find inter-relationships among the measurements.

\section{Results and Discussion}

\section{Measurement of fluency}

Table 1 provides the detailed information for fluency under planned and unplanned conditions. The analysis gives the actual mean scores for the comparisons of each student's speech rate in order to show differences in their oral speech under planned and unplanned conditions.

Table 1. Mean scores for fluency under planned and unplanned conditions

\begin{tabular}{lcccccccc} 
Participants & $P 1$ & $P 2$ & $P 3$ & $P 4$ & $P 5$ & $P 6$ & $P 7$ & $P 8$ \\
\cline { 2 - 8 } & per sec & per sec & per sec & per sec & per sec & per sec & per sec & per sec \\
$\begin{array}{c}\text { Mean } \\
\text { Scores }\end{array}$ & 1.83 & 1.70 & 2.07 & 4.30 & 2.7 & 1.89 & 2.89 & 3.14 \\
$\begin{array}{c}\text { Under unplanned } \\
\text { conditions }\end{array}$ & 1.46 & 0.38 & 3 & 3.54 & 2.54 & 1.7 & 3.41 & 2.38 \\
$\begin{array}{c}\text { Under planned } \\
\text { conditions }\end{array}$ & -0.37 & -1.32 & +0.93 & -0.76 & -0.16 & -0.19 & +0.52 & -0.76 \\
$\begin{array}{c}\text { The dynamic of } \\
\text { change }\end{array}$ & & & & & & & & \\
\hline
\end{tabular}


The results indicate that only two participants had increased their speech rate following their individual planning time. For example, the dynamic changes for $\mathrm{P} 3$ is +0.93 and for $\mathrm{P} 7$ is +0.52 . The other five participants P1, P4, P5, P6 and P8 had low mean scores under planned conditions. The results of the participants had the following dynamic ranges: -0.37 , $-0.76,-0.16,-0.19$, and -0.76 . According to Skehan's complexity-accuracy-fluency framework, planned conditions seem to have an effect on speech rate; however, this tendency was not observed in the current research.

In addition, there was a participant whose results were significantly higher under unplanned conditions. For example, the range in scores across the tasks for P2 had a dynamic change of -1.32. In contrast, unplanned conditions led to much more uneven result for P3 and P7. The reason for these results can potentially be explained by two factors. First, unplanned conditions lead to spontaneous and fluent speech and less accurate speech, which means that the participant produced a lower level of accuracy and made more grammar errors. In terms of the other students, they were more accurate in their speech, used more grammatically correct forms, provided more diverse utterances, and used more complete sentences. Second, there was the construction of logical text under planned conditions in which the participant produced a lower rate of speech but the most accurate level of oral performance. The level of accuracy of oral performance depends on the difficulty of the task as well. The same task can be difficult to complete for one person and easier for another.

Generalizing these results, there is no great difference between planned and unplanned conditions on speech rate. The results show that fluency is not greater under planned conditions. It should be noted that in this experiment the planning time for the narrative task did not promote a greater degree of fluency, suggesting that there is no necessity for planning.

\section{Measurement of vocabulary diversity}

To measure the diversity of the vocabulary used by the participants, a program called D-Tools was used, which evaluates D value for small texts, as well as a program called P-Lex, which assesses the vocabulary used in short texts. Housen, Kuiken, Vedder emphasize that "some lexical diversity measures are text-internal, i.e. they only use information from the actual text itself. There is a need for a text-external measure that uses some sort of reference material to compute an index of lexical variety". In addition, a measure of lexical sophistication, or Lambda (the number of infrequent words) was used alongside another measurement of lexical diversity called the $\mathrm{D}$, which reflects the extent to which speakers avoid recycling a small number of the same words. Lambda shows the extent to which a speaker accesses less frequent words from the second language lexicon.

Table 2 presents the comparable results for Lambda and for $\mathrm{D}$ value. In the tasks under planned conditions, five of the eight participants (P1, P3, P4, P5, P8) produced higher Lambda figures $(1.526,1.866,1.578,1.5,1.4)$ than in the tasks under unplanned conditions $(1.333,1.5,0.833,1.288,0.571)$. The data would seem to suggest that under planned conditions, participants draw upon a wider range of infrequent lexis, reflecting their richer, more accessible, and more organized lexicons. It should be mentioned that one participant (P7) demonstrated the use of less frequent words on the same level (1) in both tasks. It can be suggested that the time conditions did not influence the lexical performance of the participant or that for this participant the level of difficulty of the presented tasks were the same. 
Table 2. Lambda and D value scores: unplanned vs. planned speech

\begin{tabular}{|c|c|c|c|c|c|c|c|c|c|}
\hline Par & ants & $P 1$ & $P 2$ & $P 3$ & $P 4$ & P5 & P6 & $P 7$ & $P 8$ \\
\hline \multirow{2}{*}{$\begin{array}{c}\text { Text } \\
\text { external } \\
\text { measures }\end{array}$} & $\begin{array}{c}\text { Lambda } \\
\text { (P-lex) } \\
\text { (unplanned } \\
\text { conditions) }\end{array}$ & 1.333 & 1.888 & 1.5 & 0.833 & 1.288 & 1.684 & 1 & 0.571 \\
\hline & $\begin{array}{c}\text { Lambda } \\
\text { (P-lex) } \\
\text { (planned } \\
\text { conditions) }\end{array}$ & 1.526 & 1.838 & 1.866 & 1.578 & 1.5 & 1.517 & 1 & 1.4 \\
\hline \multirow{2}{*}{$\begin{array}{c}\text { Text } \\
\text { internal } \\
\text { measures }\end{array}$} & $\begin{array}{l}\text { D value } \\
\text { (D-Tools) } \\
\text { (unplanned } \\
\text { conditions) }\end{array}$ & $\mathrm{D}=48.4$ & $\mathrm{D}=37.7$ & $\mathrm{D}=55.4$ & $\mathrm{D}=33$ & $\mathrm{D}=45.5$ & $\mathrm{D}=42.8$ & $\mathrm{D}=49.5$ & $\mathrm{D}=49.5$ \\
\hline & $\begin{array}{c}\text { D value } \\
\text { (D-Tools) } \\
\text { (planned } \\
\text { conditions) }\end{array}$ & $\mathrm{D}=55.8$ & $\mathrm{D}=51$ & $\mathrm{D}=47.6$ & $\mathrm{D}=37.4$ & $\mathrm{D}=48.5$ & $\mathrm{D}=51.4$ & $\mathrm{D}=47.8$ & $\mathrm{D}=49.2$ \\
\hline
\end{tabular}

It should be noted that after comparing answers for the task with spontaneous speech and for the task including preparation time, it was found that the vocabulary diversity (D value) occurred to be high among five participants: P1, $\mathrm{P} 2$, P4, P6, and P5 $(\mathrm{D}=55.8, \mathrm{D}=51, \mathrm{D}=37.4, \mathrm{D}=48.5, \mathrm{D}=51.4)$. It indicates that there is a positive relationship between lexical diversity and quality of spoken discourses of candidates. It can be suggested that the results correspond to Skehan's research which shows that "pre-task planning produces greater lexical complexity".

Measurement of Accuracy

Another factor which was measured and compared based on planned and unplanned conditions was accuracy. It is important to mention that there was not any available software which allowed for the accurate measurement of spoken data. Consequently, the transcriptions were measured by taking as reference "Appendix C error guidelines" in Polio. Thus, it was necessary to count the numbers of grammatically correct clauses and then divide them by the total of number of clauses. In this way, the ratio of error free clauses could be obtained.

The analysis of the data collected from the unplanned conditions did not show a significant difference compared to the planned task. The results of the participants had the following ranges: $0.89,0.91,0.95,0.96$, and 1 . There results show that some of the participants made between 1 to 3 mistakes in building grammatically correct clauses. It is necessary to mention that 3 of the 8 participants did not make any grammatical mistakes while they were speaking. On the other hand, it can be seen in Table 3 below that most of the participants presented a high ratio of error free clauses under planned conditions, with higher ratios reflect a higher level of accuracy. Most of the participants scored a ratio of 1 which means the number of grammatical correct clauses was exactly the same as the number of clauses in the text. There was only one participant whose ratio was 0.85 . There were 4 grammatically incorrect clauses from a total of 27 which does not represent a significant difference.

There could be a number of reasons for these results. All of the participants are studying to obtain a Master degree in English Studies which means that they often interact in English. However, during the analysis of the recording, it can be perceived that one of the participants was a slightly anxious, and it coincided with the fact that this student made the most of the mistakes in building grammatically correct clauses under planned conditions, while the opposite occurred under unplanned conditions. In addition, it is also important to note other phenomena that were observed in this phase of analysis. The data showed that features such as repairs, repetitions, rephrasing, numerous parentheses, and pauses were present. Some researchers referred them to "various strategies to compensate for students' lack of words to maintain monologue". Most of the participants under planned or unplanned conditions repaired their sentences when they noticed that they had made a mistake. These features reflect the grammatical knowledge of the participants. Table 3 provides additional information about the data below. 
Table 3. The effects of unplanned and planned conditions on accuracy

\begin{tabular}{|c|c|c|c|c|c|c|c|c|}
\hline Participants & & $P 2$ & $P 3$ & $P 4$ & $P 5$ & P6 & $P 7$ & $P 8$ \\
\hline clauses & $P I$ & $P 2$ & $P 3$ & $P 4$ & $P J$ & $P O$ & $P 7$ & $P 8$ \\
\hline $\begin{array}{c}\text { Under } \\
\text { unplanned } \\
\text { conditions }\end{array}$ & 0.91 & 1 & 0.95 & 0.89 & 0.96 & 0.95 & 1 & 1 \\
\hline $\begin{array}{l}\text { Under plannec } \\
\text { conditions }\end{array}$ & 1 & 1 & 1 & 0.94 & 1 & 0.85 & 1 & 1 \\
\hline
\end{tabular}

The second research question reflects the aim to better understand what aspects students focused on during the individual planning time provided to them. The participants were asked to answer the question immediately after completing the tasks. Most of the participants agreed that the logical order of the pictures, the organization of the ideas, and coherence were important considerations under the planned condition. They used their planning time effectively and looked for possible strategies that could help them to become successful in accomplishing the task.

\section{Summery}

The first research question investigated in this study concerned the role of planning on different variables of fluency, vocabulary complexity, and accuracy in oral teaching methods. First, the research shows that planning time has an effect on lexical sophistication. Participants integrating more infrequent words with more accurate language performance while completing the task with preparation time. During the data analysis, it was found that the lexical richness in second language production under planned conditions was higher among most of the participants. This suggests that pre-task planning influences vocabulary diversity. Lexical complexity can be considered as an apparent sign of learners' general language proficiency and an essential indicator of the quality of their speaking teaching methods.

Second, the results suggest that fluency under unplanned conditions had higher mean scores than under planned conditions. Students showed their capacity to cope with real-time oral teaching methods, however under unplanned conditions they tried to avoid using complex sentences in the process of creation logical and coherent narration. The evidence presented here suggests that the planning process does not have an impact on fluency. On the other hand, planning provides more accurate, complex, and structured speech.

Third, accuracy under unplanned conditions was not significantly affected. While there were some mistakes in the production of grammatically correct clauses, but it did not exceed the number of four errors. On the other hand, most of the participants who worked under planned conditions demonstrated a high ratio of accuracy with the exception of one student whose results can be attributed to anxiety demonstrated by the participant. Moreover, it should be noted that the English proficiency of the students likely played a significant role, since most of them are studying to obtain a Master's degree in English Studies. It means that their English abilities are developed enough for them to perform well under unplanned or planned conditions in terms of accuracy. However, during the comparison of the stories that they produced, it could be observed that the narratives they produced under planned conditions were better structured, logically well-constructed, and more interesting.

\section{Conclusions}

Regarding the second research question about what the students' main concerns during their individual planning time, the answers that were obtained showed that students used their time to implement the most effective strategies for the successful performance of the narrative task. This gave them the opportunity to use their imagination efficiently, to focus on form, plot, organization of ideas, logical order of the pictures, coherence.

\section{Acknowledgements}

The work is performed according to the Russian Government Program of Competitive Growth of Kazan Federal University. 


\section{References}

Birch, G. (2005). Balancing fluency, accuracy, and complexity through task characteristics. Teachers exploring tasks in English language teaching, 228-241.

Ellis, R. (2003). Task-based language learning and teaching. Oxford University Press, 7(3), 398.

Foster, P., Tonkyn, A. \& Wigglesworth, G. (2000). Measuring spoken language: A unit for all reasons. Applied Linguistics, 21(3), 354-375.

Fujo, M. H. \& Dida, M. A. (2019). Centralized Admission System for Advanced Level Private Schools: Case of Kilimanjaro Region, Tanzania. Journal of Information Systems Engineering \& Management, 4(1).

Housen, A., Kuiken, F. \& Vedder, I. (2012). Dimensions of L2 performance and proficiency: Complexity, accuracy and fluency in SLA. John Benjamins Publishing, 32, 305.

Jenaabadi, H. \& Shad, E. M. (2013). Study of Attitude Of Middle School Students Toward Schools Counselors' Efficacy In Helping Them To Solve Their Study, Job Personal And Family Problems. UCT Journal of Social Sciences and Humanities Research, 1(1), 22-24

Long, M. (2014). Second language acquisition and task-based language teaching, John Wiley \& Sons, 456.

Murzinova, K. E. A., Koblanova, A. \& Ansabayeva, D. A. A. (2018). Prosodical means applied in communicative relations. Opción, 34(85-2), 61-96.

Polio, C. (1997). Measures of linguistic accuracy in second language writing research. Language learning, 47(1), 101-14

Puspitasari, L., In'am, A. \& Syaifuddin, M. (2019). Analysis of Students' Creative Thinking in Solving Arithmetic Problems. International Electronic Journal of Mathematics Education, 14(1), 49-60. https://doi.org/10.12973/iejme/3962

Solnyshkina, M., Solovova, E., Harkova, E. \& Kiselnikov, A. (2016). Language Assessment Course: Structure, Delivery and Learning Outcomes. International Journal of Environmental and Science Education, 11(6), 1223-1229.

Skehan, P. (2009). Modelling second language performance: Integrating complexity, accuracy, fluency, and lexis. Applied linguistics, 30(4), 510-532.

Solnyshkina, M., Ziganshina, C., Sharifullina, E. \& Gatiyatullina, G. (2016). The Effect of Pre-Task Strategic Planning on Russian A2 EFL Learners' Monologic Oral Performance. International Journal of Humanities and Cultural Studies, 3(2), 255-262.

Tarasova, F., Mukharlyamova, L., Ashrapova, A., Mukhametzyanova, L., Shayakhmetova, L. \& Ilyasova, L. (2016). Active Approach in Teaching Grammar to Bilingual EFL Learners". Journal of Current Research in Science, 4(1), 94.

Yarmakeev, I., Gafiyatova, E., Korovina, I. \& Solnyshkina, M. (2017). Deictic Elements as Means of Text Cohesion and Coherence in Academic Discourse. Journal of Social Studies Education Research, 8(3), 190-200. 